\title{
ANORMALIDADES DO LIQUIDO CEFALORRAQUEANO EM 170 CASOS DE AIDS
}

\author{
J.A. LIVRAMENTO* - L.R. MACHADO* - A. SPINA-FRANGA **
}

\begin{abstract}
RESUMO - Foi estudado sistematizadamente o líqüido cefalorraqueano (LCK) de 170 pacientes com sindrome de inuunodeficiência adquirida (AIDS). Todos apresentavam títulos positivos no soro para o vírus da imunodeficiencia humana (HiV). Em todos havia sinais e sintomas sugestivos de comprometimento do sistema nervoso. $\theta$ periodo do estudo esteve compreendido entre julho de 1984 e abril de 1989. Dos 170 casos estudados, 8 (4,7\%) apresentavam exame de LCR dentro dos limites nornıais. Células neoplásicas (linfonta) foram observadias em três casos. Meningite asseptica de etiologia não esclarecida foi encontrada em 34 casos $(20,1 \%)$. Em 88 casos foi possivel determinar, no LCK, alteraçies que permitiram o diagnustico etinłógico. Destes, 78 casos apresentavam acometimento do SN de etiologia infecciosa: criptococose ocorreu em $23(35,9 \%)$; toxoplasmose em $20(\mathbf{2 5 , 6 \% )}$; sifilis em 10; candidiase em 3; doenca de Chagas em 2; tuberculose em 1; nocardiose em 1; esquistossomose em 1. Presenra de anticorpos para outros virus foi detectada em 7 casos. Bactérias foram isoladas em 5 casos. A pesquisa de anticorpos anti-HIV foi efetuada no LCR em 55 casos, tendo resultado positiva em $48(87,3 \%)$. Associação de duas ou mais etiologias infecciosas ocorreu em 15 casus. Disscute-se a importancia do exame do LCR sistematizado nos casos com suspeita ou comprovaçăo diagnóstica de AIDS.
\end{abstract}

\section{Cerebrospinal fluid abnormalities in 170 cases of AIDS.}

SUMMARY - Cerebrospinal fluid (CSF) was analysed in 170 AIDS patients. All of them showed HIV positive serological tests. All of themi showed neurologic syndromes related to AIDS. The time period of the investigation was July 1984 - April 1989 . In 8 cases (4.7\%) CSF composition was normal. Lymphoma cells were observed in three cases. Aseptic meningites occurred in 34 cases $(20.1 \%)$. Aetiological diagnosis of associated infection was established in 88 cases: cryptococcosis in 28 (35.9\%); toxoplasmosis in 20 (25.6\%); syphilis in 10; candidiasis in 3; Chagas disease in 2 ; tuberculosis in 1; nocardiosis in 1; schistosomiasis in 1. Antibodies for other virus were detected in 7 . Bacteria were isolated in 5 cases. Anti-HIV antibodies were tested in CSF samples of 55 cases: they were found in 48 ( $87.3 \%$ ). Two or more associated infections were observed in 15 cases. Changes of csF composition in AIDs are discussed taking into account changes reported.

A infecçāo pelo virus da imunodeficiência adquirida (HIV) espalha-se rapidamente por todos os continentes transformando-se, em apenas 7 anos, num dos problemas prioritários para a saúde pública mundial 3,5 . São cada vez mais freqüentes, precoces e duradouras as lesōes causadas pelo virus da AIDS no sistema nervoso (SN). Ho et al., em 1985, enfatizaram a importância das lesōes do SN na AIDS postulando que 'o SN é um santuário do virus da AIDS' 2. Para diagnóstico de comprometimento do $\mathrm{SN}$ destacam-se na atualidade, a tomografia computadorizada cerebral, a ressonância magnética e o exame do líquido cefalorraqueano (LCR). Em 1987, Spina-França et al. apresentaram análise sistematizada do LCR de 50 pacientes com AIDS: em apenas cinco $(10 \%)$ o exame do LCR era normal 8 .

Trabalho do Centro de investigaçeses em Neurologia (CIN), Departamento de Neurologia, Faculdade de Medicina da Ĺniversidade de São Paulo (FMUSP): * Médico Assistente; **Professor Titular. 
O objetivo deste artigo é relatar os resultados do estudo do LCR de 170 pacientes com AIDS, dando continuidade à pesquisa iniciada por este grupo de trabalho em $1987^{8}$.

\section{MATERIAL E MÉTODOS}

Foram estudadas 316 amostras de LCR de 170 pacientes com AIDS, todos com testes para HIV positivos no soro e nos quais vigência de sintomatologia neurológica constituiu a indicação para o exame do LCR. O período da investigação foi de julho de 1984 até abril de 1989 (Tabela 1). Três pacientes eram do sexo feminino e 167 eram do sexo masculino; 165 eram brancos e 5 pardos ou pretos. Suas idades variaram entre 23 dias e 70 anos (média: 33,5 anos). Todos apresentavam fatores de risco para a afeç̧ão. As amostras de $L C R$ foram colhidas via lombar em 26 casos e da cisterna magna nos restantes. Em 110 pacientes o LCR foi analisado em uma ocasião (primeira amostra) e em mais de uma nos 60 restantes (máximo 29 vezes). Para a finalidade desta investigação foram consideradas as caracteristicas da primeira amostra de LCR: dados sobre amostras subseqüentes sāo referidos quando introduziram novos elementos de ordem diagnóstica. Em todas as amostras foi realizado de maneira sistematizada o exame do LCR, abrangendo o estudo de: pressão (possível em 151 casos); aspecto e cor: citologia (número global de células/mm3 e perfil citomorfológico); concentraçāo de proteínas, cloretos e glicose; perfil eletroforético das proteínas (possivel em 137 casos); atividade enzimática de TGO e DHL (possivel em 50 casos); subpopuiações linfocitárias (possivel em 18 casas); reações de fixação do complemento (RFC) para sifilis e císticercose: reaçāo de floculaçăo para sífilis (VDRL); reaçôes de imunofluorescência (IgG) indireta (RIF) para cisticercose, toxoplasmose, sifilis (FTA-Abs) e, nos casos com sintomatologia meduiar (15 casos), também para esquistossomose; exame bacteriológico (direto e culturas) para bactérias e micobactérias; exame micológico, abrangendo pesquisa direta. culturas e pesquisa de antígeno solúvel de Cryptococcus neoformans: pesquisa de anticorpos por reação de fixação do complemento (RFC) para citomegalovírus, herpes simplex virus tipo 1 e varicela zóster virus em 58 casos; pesquisa de anticorpos anti-Hlv por ensaio imunoenzimático (ELISA) em 55 casos. Todos os exames foram realizados no mesmo laboratório e em todas as amostras foi utilizada a mesma técnica, seguindo os métodos adotados no CIN e sendo interpretados segundo os critérios de normalidade previamente determinados (8).

Ano

Número de casos

\begin{tabular}{cc}
\hline$-1984(6 \mathrm{~m})$ & 4 \\
1985 & 13 \\
1986 & 20 \\
1987 & 34 \\
1988 & 70 \\
$1989(4 \mathrm{~m})$ & 29 \\
\hline
\end{tabular}

Tabela 1 - Distribuição do námero de casos de AIDS no período de estudo (3/7/84-27/4/89). Notar que em 1984 e 1989 o periodo de estudo foi de 6 e 4 meses (m) respectivamente.

\section{RESLLTADOS}

As alteracōes do LCR observadas nos 170 casos de AIDS estudados constam da tabela 2. A distribuição de freqüéncias nos 88 casos en que foi possível a identificação de agente etiológico pelo exame do LCK consta da takela 3.

A discriminação dos 15 casos em que ocorreu associação de dois ou mais agentes etiológicos é apresentada na tabela 4. Descrição qualitativa do comportamento do LCR nos $2 \delta$ casos que arresentavam neurocriptococose consta da tabela 5 . 


\begin{tabular}{|c|c|c|}
\hline Alteração & Número de casos & $\%$ \\
\hline Punçāo branca & 1 & 0,6 \\
\hline Hipertensāo & 29 & 19,2 \\
\hline Hemorragia & 7 & 4,1 \\
\hline Xantocromia & 74 & 43,7 \\
\hline Hipercitose & 76 & 44,9 \\
\hline Proteinas totais: aumento & 115 & 68,0 \\
\hline Cloretos: diminuição & 42 & 24,8 \\
\hline Glicose: diminuição & 48 & 28,4 \\
\hline Gamàglobulinas: aumento & 94 & 68,6 \\
\hline Subpopulaçôes linfocitárias & 7 & 38,9 \\
\hline TGO: aumento & 18 & 36,0 \\
\hline DHL: aumento & 25 & 50,0 \\
\hline Meningite asséptica * & 34 & 20,1 \\
\hline Agente etiológico presente & 88 & 52,1 \\
\hline
\end{tabular}

Tabela \&-Alteracōes do LCR encontradas em 170 casos de AIDS. Valores percentuais referentes ao número de casos nos quais o evento foi estudado. * Sem etiologia detectada. Em 8 casos $(4,7 \%)$ o LCR näo apresentava alterasóes.

\begin{tabular}{lcc}
\hline Alteraçăo & Número de casos & $\%$ \\
\hline Hemorragia & 7 & 8,0 \\
Neoplasia & 3 & 3,4 \\
Infecção & 78 & 88,6 \\
Criptococose & 28 & 35,9 \\
Toxoplasmose & 20 & 25,6 \\
Sifilis & 10 & 12,8 \\
Candidiase & 3 & 3,8 \\
Chagas & 2 & 2,6 \\
Tuberculose & 1 & 1,3 \\
Nocardiose & 1 & 1,3 \\
Esquistossomose & 1 & 1,3 \\
Virus & 7 & 9,0 \\
Bactérias & 5 & 6,4 \\
HIV positivo & 48 & 87,3 \\
\hline
\end{tabular}

Tabela 3 - Distribuição dos 88 casos de AIDS em que foi possivel a identificasāo de agente etiologico pelo exame do LCR. Valores percentuais referentes ao numero de casos em que o evento foi observado. Para o HIV positivo notar que em somente 55 dos 170 casos estudados, o evento foi pesquisado (a partir de novembro de 1988 ). 


$\begin{array}{lcr}\text { Criptococose + toxoplasmose } & 3 & 20,0 \\ \text { Criptococose + candidiase } & 1 & 6,7 \\ \text { Criptococose + sifilis } & 1 & 6,7 \\ \text { Criptococose + herpes 1 (vímus) } & 1 & 6,7 \\ \text { Criptococose + toxoplasmose + sifilis } & 1 & 6,7 \\ \text { Toxoplasmose + sífilis } & 2 & 13,3 \\ \text { Toxoplasmose + tuberculose } & 1 & 6,7 \\ \text { Candidiase + esquistossumose } & 1 & 6,7 \\ \text { Sifilis + herpes 1 + varicela zóster } & 1 & 6,7 \\ \text { Varicela zoster + herpes 1 } & 2 & 13,3 \\ \text { Varicela zóster + Proteus sp } & 1 & 6,7\end{array}$

Tabela 4 - Diagnóstico estabelecido pelo exame do LCR em 15 de casos de AIDS nos quais observou-se associaçāo de agentes etiologicas. Valores percentuais para o número de casos em que associagão etiologica de agentes infecciosos foi observada.

Criptococose: 28 casos

\begin{tabular}{|c|c|c|c|}
\hline Cit. & Prot. & Glic. & Freq. \\
\hline $\mathrm{n}$ & $n$ & $n$ & $\varepsilon$ \\
\hline $\mathrm{n}$ & $\mathrm{n}$ & d & 1 \\
\hline $\mathrm{n}$ & a & $\mathbf{n}$ & 3 \\
\hline $\mathrm{n}$ & $\mathrm{a}$ & $d$ & 3 \\
\hline a & $\mathrm{n}$ & $\mathrm{n}$ & 1 \\
\hline a & $\mathrm{n}$ & $\mathrm{d}$ & 1 \\
\hline a & a & $\mathrm{n}$ & 6 \\
\hline a & a & $\mathrm{d}$ & 5 \\
\hline
\end{tabular}

Tabela 5 - Comportamento do nümero global de células por mms (Cit.); concentnacāo de proteinas totais (Prot.) e glicose (Glic.) em mg/dl nos 28 casos em que houve comprovasāo do diagnostico de neurocriptococose. $n$, normal; a, aumento; d, diminuigäo; freq., número de casos em que o evento foi observado.

\section{COMENTARIOS}

Comprometimento do SN na AJDS pode ocorrer em qualquer fase da doença: desde os estágios precoces da infecção, na soroconversão, no complexo relacionável à AIDS (ARC) e na sindrome de imunodeficiência propriamente dita. Alteraçóes quanto ao comportamento do dual citoproteico do LCR são verificadas nas diversas fases da doença, sobretudo nos estágios precoces 6,8. Presença de infecções oportunistas caracteristicas da fase de imunodeficiência propriamente dita encontram no exame do LCR a melhor maneira de estudo 4,8 . 
Dos 170 casos estudados em apenas um não houve saida de LCR espontaneamente ou por aspiração, apesar da sensação de posicionamento da agulha na cisterna magna; o paciente encontrava-se em coma profundo, tendo como antecedente o uso de drogas. Hipertensão do LCR foi observada em 29 casos, sobretudo naqueles que apresentavam neurocriptococose. Hemorragia foi observada em 7 casos sendo associada, em dois, à presença de células neoplásicas (linfoma). Xantocromia foi verificada em 43,7\% dos casos. As alteraçōes do dual citoproteico observadas foram: aumento do número de celulas em 44,9\%; hiperproteinorraquia em $68,6 \%$ dos casos estudados. Diminuiçăo de glicose e cloretos foi verificada respectivamente em $28,4 \%$ e $24,8 \%$ dos casos, correspondendo àqueles casos que apresentavam evidência de etiologia infecciosa. Alterações de subpopulações linfocitárias como diminuiçăo de linfócitos $\mathrm{T}$-ativos e aumento de iinfócitos $\mathrm{T}$-sensibilizados foi o fenômeno predominantemente observado, ocorrendo em $38,9 \%$ dos casos em que foi possivel o seu estudo. Aumento da atividade enzimática de TGO e DHL foi observado em $36 \%$ e $50 \%$ dos casos, respectivamente.

O SN apresenta características imunológicas especiais, graças à existência de barreira hèmato-encefálica e à ausência de estruturas linfóides organizadas 1 . É possivel que estas particularidades estejam relacionadas à ocorrência freqüente de infecçōes oportunistas no SN em pacientes com AlDS. Nesta investigaçăo foi possivel identificar presença de agente etiológico em 88 casos $(52,1 \%)$.

Meningite asséptica, quadro frequientemente constatado nas fases iniciais da afecção, foi observada em $20,1 \%$ dos casos. Este diagnóstico tem sido feito com maior freqüência a partir de 1988 devido ao maior grau de informaçāo sobre a doença entre os neurologistas 2,3 .

Foi detectada flora bacteriana no LCR de 5 pacientes $(6,4 \%)$ : Klebsiella sp em um; Aerobacter sp em um; Proteus mirabilis em um; Staphylococcus aureus eni um; bacilos Gram negativos năo identificados em um. Em 28 casos $(35,9 \%)$ foi verificada a presença de Cryptococcus neoformans, quer pelo exame direto quer pela pesquisa de antigeno solúvel e sempre comprovada por identificação em culturas em meio de Sabouraud; deve ser salientado que em 15 casos $(53,6 \%)$ o número de células no LCR estava dentro dos limites normais; 8 casos apresentavam número de células, proteinas e glicorraquia normais. A criptococose e a toxoplasmose representam classicamente as duas afecçōes observadas com maior frequiência $3,4,8$. Dados de agosto de 1986 do CDC, em Atlanta, EUA, referem maior incidência de criptococose em relação à toxoplasmose 4 . Este fato foi observado também no material ora em estudo (35.9\% criptococose; $25,6 \%$ toxoplasmose). Associaçōes de duas ou mais infecçōes foram evidenciadas em 15 pacientes $(17,4 \%)$. A mais freqüente foi a associação criptococose-toxoplamose verificada em três casos $(20 \%)$, Outras patologias infecciosas do SN, também foram observadas: sífilis $(12,8 \%)$, candidiase $(3,8 \%)$, doença de Chagas $(2,6 \%)$, tuberculose $(1,3 \%)$, nocardiose $(1,3 \%)$, e esquistossomose $(1,3 \%)$. Nos dois casos com doença de Chagas houve comprovação do agente etiológico ao exame direto; em ambos a reaçāo de imunofluorescência foi reagente 9 . Presença de anticorpos para outros virus foi verificada em 7 casos $(9,0 \%)$; no entanto, foram pesquisados apenas anticorpos para citomegalovirus, herpes simplex vírus tipo 1 e varicela zóster vírus; apenas os dois últimos foram detectados. Presença de anticorpos anti-HIV no LCR passou a ser pesquisada como rotina a partir do final de 1988 . De 55 casos estudados, $48(87,3 \%)$ apresentaram resultados positivos. Linfomas primários do SN têm sido observados em aproximadamente $1,9 \%$ de pacientes com AIDS 7; neste estudo foi possível a detecção de células neoplásicas de tipo linfomatoso no LCR em três casos $(3,4 \%)$.

Na tabela 2 mostra-se que em apenas 8 casos $(4,7 \%)$ o exame de LCR era normal. Este fato torna evidente a necessidade do estudo sistematizado do exame de LCR em pacientes com AIDS. Em particular, devem ser procurados insistentemente agentes infecciosos, de modo especial aqueles de tipo oportunista, sejam vírus ou leveduras. $O$ exame do LCR pode fornecer informaçoes relevantes desde que seja pré-estabelecida rotina de pesquisa especifica para agentes infecciosos em todos os casos suspeitos ou com diagnóstico de AIDS. 


\section{REFERENCIAS}

1. DeMicco C, Toga M - Le statut immunitaire du systeme nerveux central. Rev Neurol (Paris) 144:776, 1988.

2. Ho DD, Toya TR, Schooley RT, Kaplan JC, Alan JD, Groupman JE, Resnick L, Felsengtein D, Andrews CA, Hirsch MS - Isolation of HTLV-III from cerebrospinal fluid and neural tissues of patients with neurologic syndromes relatet to the acquired immunodeficiency virus. N Engl J Med 313:1493, 1985.

3. Jansen RS, Cornblath DR, Epstein LG, McArthur J, Price RW - Human immunodeficiency virus (HIV) infection and the nervous system: report from the American Academy of Neurology AIDS Task Force. Neurology 39:119, 1988.

4. Levy RM, Bredesen DE, Rosemblum ML - Opportunistic central nervous system pathology in patients with AIDS. Ann Neurol 23 (Suppl): S7, 1988.

5. Lifson AR, Rutherford GW, Jaffe $\mathrm{HW}$ - The natural history of human immunodeficiency virus infection. $J$ Infect Dis 158:1360, 1988.

6. McArthur JC, Cohen BA, Farzedegan IA, Cornblath DK, Selnes OA, Ostrow D, Johnson RT, Phair J, Polk BF - Cerebrospinal fluid abnormalities in homosexual men with and without neuropsychiatric findings. Ann Neurol 23 (Suppl): S34, 1988.

7. Rosemblum ML, Levy RM, Bredesen DE, So YT, Wara W, Ziegler JL - Primary central nervous system lymphomas in patients with AIDS. Ann Neurol 23 (Suppl): S13, 1988.

8. Spina-França A, Livramento JA, Machado LR, Bacheschi LA, Nóbrega JPS - Liqüido cefalorraqueano na sindrome de imunodeficiência adquirida: análise de 50 casos. Arq Neuro-Psiquiat (São Paulo) 45:412, 1987.

9. Spina-França A, Livramento JA, Machado LR, Yasuda N - Anticorpos a Trypanosoma cruzi no liquaido cefalorraqueano: pesquisa pelas reacões de fixação do complemento e de imunofluorescência. Arq Neuro-Psiquiat (Sāo Paulo) $46 \cdot 374,1988$. 